\title{
Religiões afro-brasileiras e a expansão das fronteiras: desafios interpretativos sobre a produção do sagrado e das identidades religiosas na contemporaneidade
}

Afro-Brazilian religions and expansion of borders: interpretive challenges on the production of the sacred and of religious identities in contemporary times

\section{Ana Paula Mendes de Miranda}

Brasil. Universidade Federal Fluminense. Professora Associada do Departamento de Antropologia e do Programa de Pós-Graduação em Antropologia da UFF; Bolsista de Produtividade 2 do CNPq; Pesquisadora dos Institutos Nacionais de Ciência e Tecnologia do Instituto de Estudos Comparados em Administração de Conflitos (INCT-InEAC); Coordenadora Adjunta dos Programas Profissionais da Capes (Área de Antropologia/Arqueologia). ID ORCID: https://orcid.org/0000-0003-1007-6714. E-mail: anapaulamiranda@id.uff.br. Colaboração: Pesquisa bibliográfica, pesquisa empírica, análise de dados, redação.

\section{Joana Bahia}

Brasil. Universidade do Estado do Rio de Janeiro. Professora Titular e Procientista do Programa de PósGraduação em História Social da Universidade do Estado do Rio de Janeiro. Doutora em Antropologia Social pelo Programa de Pós-Graduação em Antropologia Social da Universidade Federal do Rio de Janeiro (PPGAS-UFRJ). ID ORCID: http://orcid.org/0000-0002-2172-5022. E-mail: joana.bahia@gmail.com. Colaboração: Pesquisa bibliográfica, pesquisa empírica, análise de dados, redação.

\section{Roberta de Mello Côrrea}

Brasil. Universidade Federal Fluminense. Doutora em Antropologia pela Universidade Federal Fluminense (UFF). Bolsista do Programa de Pós Doutorado (PNPD) da Capes, do Programa de Pós-Graduação em Antropologia da Universidade Federal Fluminense (PPGA-UFF). Pesquisadora do Núcleo Fluminense de Estudos e Pesquisas da Universidade Federal Fluminense (NUFEP-UFF) e do Institutos Nacionais de Ciência e Tecnologia do Instituto de Estudos Comparados em Administração de Conflitos (INCT-InEAC). ID ORCID: https://orcid.org/0000-0002-7143-889X. E-mail: robertamcorrea@yahoo.com.br. Colaboração: Pesquisa bibliográfica, pesquisa empírica, análise de dados, redação.

A produção acadêmica sobre o lugar do Brasil numa cartografia religiosa contemporânea, no que se refere à difusão e ao consumo global de práticas e identidades religiosas, tem destacado como algumas das causas desse processo a migração de brasileiros, a partir dos anos 1980; a difusão por meios de comunicação e 
pela internet de programas com conteúdos religiosos, em sua maioria de natureza neopentecostal; e o reavivamento de um imaginário sobre o Brasil, com sua "cultura e religiões como exóticas" (ROETT, 2010; ROCHA; VÁSQUEZ, 2014).

Estudos das Organizações das Nações Unidas (ONU) e da Organização Internacional para as Migrações (OIM) indicam que a maioria dos brasileiros emigra para os Estados Unidos, seguido pela Europa ${ }^{1}$. Em geral, estudos mostram que a emigração dos brasileiros, a partir dos anos 1980, além de ser resultante da crise econômica brasileira, está relacionada à existência de redes migratórias nos países de destino que incentivam e facilitam a viagem (FRIGERIO, 1999; PADILLA, 2006).

Embora os fatores econômicos desempenhem um papel importante na emigração, a migração também envolve aspectos sociais e culturais (PATARRA, 2005), dos quais destacamos os religiosos (LEVITT, 2007; MARTES, 1999). Empresários religiosos brasileiros emigram para fins missionários, e cada vez mais os religiosos brasileiros são importantes na criação e na continuidade de redes sociais transnacionais (BESERRA, 2006; MACHADO, 2006; SHERRINGHAM, 2013)2.

Assim, se a migração é importante para a difusão das ideias religiosas e práticas, não é possível explicar a globalização religiosa apenas em termos de padrões de migração. Não obstante as viagens desempenhem um papel fundamental, cabe ressaltar que muitos europeus, americanos e outras nacionalidades buscam as religiões brasileiras em seu país de origem sem a mediação de um brasileiro emigrante, quanto no chamado turis-

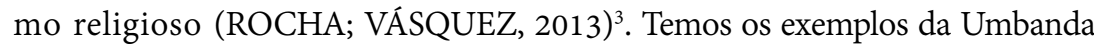
no Canadá (MEINTEL; HERNANDEZ, 2013) e na Alemanha (BAHIA 2012,

Sobre o tema ver Assis (2013), Povoa Neto (2007) e Siqueira (2014).

2 Ao contrário do que os próprios imigrantes esperam, estes indivíduos são cada vez mais criminalizados, particularmente as mulheres (PADILLA, 2006; PONTES, 2004), um fenômeno que se intensificou após os ataques de 2001 ao World Trade Center de Nova Iorque (ASSIS; MARTINS, 2010a, 2010b), e mais recentemente com a política do governo Trump.

3 A exemplo temos o documentário "Espaço Além Marina Abramovic e o Brasil" protagonizado pela artista plástica iugoslava Marina Abramovic (ESPAÇO..., 2016), em que ela mesmo realiza experiências espirituais viajando pelo Brasil, transitando desde o atendimento espiritual de João de Deus, terreiro de Candomblé, Santo Daime e outros, passando por cânticos, preces, cultos, cirurgias espirituais e todo elenco de práticas religiosas. 
2013, 2015b; SILVA, 2014), Santo Daime na Espanha (GREGANICH, 2020), Umbanda (PORDEUS JÚNIOR, 2000) e Candomblé em Portugal (CORRÊA, 2004; CORREAA, 2016; GUILLOT, 2009, 2012; SARAIVA, 2010, 2013) em que seus líderes tiveram contato com a religião ao se deslocarem para o Brasil ou mesmo para outras partes do mundo em que puderam vivenciar a experiência religiosa (BAHIA, 2015b; SILVA, 2014). Neste sentido, a difusão das religiões brasileiras também ocorre através de turistas que viajam de e para o Brasil, e através da circulação de objetos e meios de comunicação religiosos e culturais (OOSTERBAHN; VAN DE KAMP; BAHIA, 2020; ROCHA; VÁSQUEZ, 2013; VAN DE KAMP, 2016, 2017).

Lembramos que essa cartografia é também influenciada pelo movimento da Nova $\mathrm{Era}^{4}$, sendo também marcada pelo estabelecimento de um mercado religioso que difundiu a ideia de que a escolha religiosa é uma decisão privada e que o indivíduo é livre para agir. Aqui o exotismo se revela como um elemento diferencial na construção das espiritualidades alternativas, por se caracterizar num modo particular de percepção estética, que domestica as pessoas, os lugares e os objetos "exóticos" no mercado mundial (HUGGAN, 2001), de forma distinta do exotismo que caracterizou a dominação imperialista, no século XIX, durante o processo de construção dos Estados-Nação.

Como as ideias religiosas jamais estiveram presas aos limites dos territórios, é preciso pensar como tem ocorrido a expansão de "novas" religiosidades. No caso, a que nos dedicamos a estudar estão associadas às matrizes afro-brasileiras, em cenários urbanos fortemente ligados à modernidade ${ }^{5}$.

A organização deste dossiê foi motivada pelo interesse em analisar as especificidades que envolvem a expansão das religiões afro-brasileiras em contextos sociopolíticos distintos, bem como os desafios teórico-metodológicos que surgem dessas pesquisas. Interessava-nos debater, a partir de pesquisas

\footnotetext{
4 Para Tavares, Duarte e Cognalato (2010), trata-se de um movimento, a partir dos anos 1980, que por ser refratário a uma caracterização ortodoxa, transforma as fronteiras do que se considerava como a "experiência do sagrado", abrindo espaço para que a religiosidade se manifeste em âmbitos terapêuticos (vivências e workshops), tendo como resultado novas produções de sentido.

5 Salienta-se aqui que, no que diz respeito à religião, as análises sobre globalização e transnacionalização enfocam que "tradição" e "modernidade" são processos simultâneos e inter-relacionados, resultando em novas oportunidades de expansão, não estando mais preocupadas com a privatização das práticas religiosas.
} 
empíricas, como as formas de expressão afro-brasileiras são criativamente produzidas e transformadas e compreender suas consequências político-religiosas. Tal perspectiva é fundamental para uma controvérsia acerca de sua permanência e reprodução no cenário contemporâneo brasileiro de ataques e perseguições a essas tradições, bem como problematizar o debate sobre o que seriam essas novas misturas de religiões, com destaque para o papel dos atores religiosos e como suas crenças e comportamentos afetam os contextos sociais estudados.

Os textos que compõem este Dossiê não utilizam o conceito de sincretismo ${ }^{6}$. Não se pode falar de pureza quando se fala de religiões, já que todas são resultantes de sínteses - locais - que integram elementos de distintas procedências, formando um novo todo, que não é um mero mosaico de peças desconexas, mas uma "síntese integradora" (FERRETTI, 1998, p. 183), que não resulta numa unidade. Quando nos referirmos às matrizes afro-brasileiras é preciso lembrar que não se trata apenas das influências de uma nação em particular - Ketu, JeJe, Ijexá, Angola etc., mas principalmente da agência ${ }^{7}$ da casa de culto em si, o que se relaciona com a trajetória de suas lideranças religiosas (COSSARD-BINON, 1976) e as disputas que caracterizam o cotidiano dos terreiros, revelando as dinâmicas internas de poder (MAGGIE, 1975) ${ }^{8}$. O que importa na controvérsia é como o fenômeno religioso se realiza, em presença de distintas tradições, produzindo sentidos diante

\footnotetext{
6 Não é o escopo de nosso texto discutir o conceito, mas vale destacar aqui que o termo foi usado pela primeira vez por Plutarco para descrever a reunião temporária de habitantes de Creta diante de um inimigo comum, resultando no sentido de grupos em guerra. Foi Erasmus quem o empregou para se referir a um acordo entre pessoas com opiniões aparentemente díspares. No século XVII, os teólogos deram-lhe uma conotação negativa, com ênfase para uma conciliação indesejável entre as diferenças teológicas cristãs, considerado uma ameaça à religião "verdadeira" (DROOGERS, 1989). O termo sincretismo foi adotado por Melville Jean Herskovits (1937) associado ao uso do método etno-histórico, como peças centrais da análise do contato cultural, para a análise dos negros no "Novo Mundo" (Brasil, Cuba, Haiti), destacando como os sistemas religiosos africanos foram afetados: "handicapped by social scorn and official disapprobation" (HERSKOVITS, 1937, p. 636).

7 O conceito é usado aqui em conformidade com os trabalhos de Sherry Ortner, que se preocupa em pensar como "a cultura (em sentido muito amplo) constrói as pessoas como tipos particulares de atores sociais" (ORTNER, 2007, p. 45), destacando que esses atores sociais, em suas vivências e práticas variáveis, possam tanto reproduzir como transformar a cultura que os constituiu.

${ }^{8}$ Greenfield e Droogers $(2001,2003)$ propõem o uso do termo processos sincréticos para dar conta das interações individuais em contextos globais, nacionais e locais.
} 
de conteúdos aparentemente divergentes (ROCHA; VÁSQUEZ, 2014), resultando numa cosmopolítica ${ }^{9}$ reveladora de assimetrias e conflitos.

Outros conceitos têm sido utilizados no debate mais amplo da transnacionalização religiosa. Greganich, em sua análise do Santo Daime, no Brasil (2011) e na Espanha (2020), se apropria do conceito de butinage ${ }^{10}$, instrumental que analisa como uma experiência intrínseca nas práticas religiosas escapa de uma tradição, sistema ou estrutura anterior, produzindo novas ligações. Os caminhos através dos quais as pessoas organizam a sua experiência têm consequências para as religiões, podendo construir ou "desconstruir" assemblages, articular valores e formulação de enunciados de identidade, ideologia e/ou política. Esse conceito é pensado para se contrapor à ideia de sincretismo e de "ricolagem religiosa" (SOARES, 2009, p. 67-68), já que a noção de "ricolagem" de Claude Lévi-Strauss (1989), seria a recomposição pela troca dos elementos religiosos "preconcebidos" culturalmente, em conformidade com as origens, baseando-se nas tradições. A bricolagem se exerce no interior de um sistema simbólico preconcebido, no qual o "bricoleur" articula com os materiais socioculturais do qual ele já dispõe, refazendo o que já foi feito, ou seja, reorganiza-se o caleidoscópio (para se utilizar da metáfora de Lévi-Strauss) com os mesmos elementos, para isso basta girá-lo e daí surgem novas composições. O conceito de butinage critica a ideia de reorganizar o que já está dado numa estrutura religiosa fechada, se apropriando dos elementos imprevistos numa experiência religiosa.

Nessa mesma linha de raciocínio (GREGANICH, 2011, 2020;SOARES, 2009), há também uma crítica direta a Bastide (1970) e ao seu conceito de sincretismo. Para a autora, "o sincretismo religioso seria um movimento orientado por uma intenção combinatória, associativa, a partir de cosmologias justapostas, hierarquicamente caracterizadas por um "princípio de cisão" ou "de corte", obedecendo a uma lógica

\footnotetext{
Referimo-nos aqui a cosmopolítica como um processo que "abrange discursos e modos de fazer política que se preocupam com seus alcances e impactos” (RIBEIRO, 2005, p. 2) globais e locais.

${ }_{10}$ Soares (2009) exemplifica o conceito se apropriando de metáforas da natureza, a exemplo as abelhas e beija-flores. Greganich (2011, p. 100) mostra que os daimistas ao se apropriarem de elementos da Umbanda "se identificam com essa metáfora, considerando-se hoje em dia todos [...] beija-flores que estão fazendo o seu jardim e polinizando outras flores". O jardim pode ser associado ao processo de butinage e as flores às outras cosmologias religiosas. O daimista, se comparado ao beija-flor, "articularia múltiplos conteúdos religiosos em uma prática religiosa: a umbandaime (GREGANICH, 2011, p. 100).
} 
da acumulação e da adição, mantendo a compartimentalização" (GREGANICH, 2011, p. 97).

Ferretti (1995) e Sanchis (2001) analisam seu uso como útil para se pensar as dinâmicas correntes do campo religioso. Entretanto o mesmo conceito ainda é pensado como algo que encobre misturas, miscigenações, processos de lutas entre grupos por certa pureza (CANCLINI, 2006, p. 19), ou ainda o termo implicitamente exacerba a equação religião e tradição, muitas vezes ignorando os modos em que tradições religiosas são construídas e mantidas pelos grupos envolvidos (ENGLER, 2011). Alguns autores se utilizam do conceito de Ulf Hannerz (1997) de hibridismo, muitas vezes também se referem aos usos literários de Bakhtin (1981) buscando ressignificações, transgressões, processos criativos, e uma crítica aos processos coloniais. Este conceito enfatiza a complexa relação entre religião e outros aspectos da cultura e da sociedade, demonstra os contextos sociais de interação, com ênfase para as estratégias de influências mútuas e a criatividade dos agentes sociais, evidenciando conflitos e impasses (ENGLER, 2011).

Mais recentemente tem havido críticas aos conceitos de diáspora e transnacionalismo, a partir da proposição de conceitos como spheres (esferas), do filósofo alemão Peter Sloterdijk (2016), juntamente com assemblages, de Deleuze e Guatarri (OOSTERBAHN; VAN DE KAMP; BAHIA 2020). Analisando os casos da IURD em vários países, vemos que mesmo se apresentando como uma igreja não diaspórica e universal, essa ainda atrai bastantes brasileiros, porém atrai consideravelmente caribenhos e luso-africanos na Bélgica, Paris e Londres (OOSTERBAHN; VAN DE KAMP; BAHIA, 2020). E mesmo na África, lugares como Maputo, Moçambique, as ligações brasileiras da Igreja Universal são cruciais para estabelecer uma conexão sagrada com um passado judaico-bíblico através da réplica do Templo de Salomão que a Igreja Universal construiu no Brasil, trazendo uma parte de Jerusalém e seu passado para o país, e do Brasil para Angola e Moçambique (OOSTERBAHN; VAN DE KAMP; BAHIA, 2020). Mais do que um fenômeno translocal, os praticantes dessas religiosidades ampliam as fronteiras dos Estados-Nação, das suas localidades, seguindo o poder (sem limites) dos espíritos e dos deuses. 
Tsing (2000 apud OOSTERBAHN; VAN DE KAMP; BAHIA, 2020) critica o conceito de transnacionalização e mostra que a globalização religiosa não se trata de adoção nas práticas locais de elementos de um fenômeno global, portanto não se referindo às reações locais das forças globais. As religiões transitam bem por conta de suas características não territoriais, entretanto isso não nos exime de se pensar a importância das trajetórias, linguagens, objetos como coprodutoras da presença do sagrado neste contexto.

Neste sentido, o conceito de spheres (esferas) contempla a ideia de "peculiaridade da intersecção", delimitações que criam espaços de experiência partilhada (SLOTERDIJK, 2016). O autor sustenta que a vida social é produzida por (ou dentro de) "bolhas" e que os homens reproduzem esferas limitadas, nas quais a vida social se torna possível (OOSTERBAHN; VAN DE KAMP; BAHIA, 2020, p. 11). Quais grupos, sujeitos, contextos produzem ideias e coisas sagradas? Em que medida essas interseccionalidades produzem experiências sagradas?

Há também releituras da transnacionalização religiosa evidenciando os processos criativos (música, dança, mercados) (CAPONE, 2001/2002, 2011; BAHIA, 2016; GUILLOT; HUET, 2012), conflitos pós-coloniais (BAHIA, 2015a; GUILLOT, 2009) vividos pelos praticantes das religiosidades afro-brasileiras.

Outro aspecto que necessita ser problematizado tem relação com a ideia de que a identidade religiosa é una e resultante de uma escolha racional, que entra em choque com o fato de que muitas pessoas declaram uma "dupla ou múltipla pertença religiosa" (RIBEIRO, 2018), o que seria um dado relevante para se pensar criticamente o conceito de religião (GIUMBELLI, 2014), constituído a partir de uma racionalidade cristã, que não expressa como se dão efetivamente as expressões de fé e religiosidade ${ }^{11}$. Esse aspecto é de fundamental importância para pensar a recepção das religiões afro-brasileiras em outros contextos já que, em vários casos relatados nos artigos que compõem este dossiê, os adeptos ao ingressarem nessas religiões mantêm vínculos com

\footnotetext{
${ }_{11}$ Claudio de Oliveira Ribeiro (2018) salienta que a atual estrutura classificatória do Censo demográfico, de 2010, contempla a opção do múltiplo pertencimento, mas não há meios de validação dessa resposta, tornando-a pouco confiável estatisticamente.
} 
outras práticas religiosas. Lembrando ainda que os conteúdos místicos, esotéricos e ocultos são formas de expressões de religiosidade já experimentadas nos contextos históricos nos quais as religiões afro-brasileiras se instalam.

Nesse sentido, consideramos que um problema ao se pesquisar nesses contextos está na forma como o(a) pesquisador(a) formula suas questões. Ao perguntar "qual é a sua religião?" o(a) pesquisador(a) revela que o seu entendimento do que significa "ter uma religião" está associado a uma ideia de "religião", vinculada à de "Igreja" como "uma base comunitária abrangente, cuja força pode ser dimensionada pela convicção no pertencimento e pela regularidade na frequentação aos cultos" (MONTERO; SILVA; SALES, 2018, p. 133). Assim, somente faz sentido a expressão "católico não praticante" para quem concebe a religião nos termos anteriormente mencionados. Tal perspectiva é incompatível com os modos de pertencimento às matrizes afro-brasileiras, dito de outra forma, não faz muito sentido falar em "macumbeiro não praticante", afinal sua identidade está diretamente relacionada com a incorporação de múltiplas práticas, que vão do "vestir o branco" na sexta-feira ao ir à missa, não apenas na condição de ia $\hat{0}^{12}$, mas para mandar rezar missas em distintas situações. Nos dois casos, a ação religiosa está misturada com a ação política, construindo um modo próprio de “fazer religião' em público" (MONTERO; SILVA; SALES, 2018, p. 132) que conjuga simultaneamente uma experiência religiosa e uma exposição de problemas públicos, constituindo uma transcendência, na qual a missão, a mobilidade e a difusão resultam na criação de cenários de conflitos (CSORDAS, 2009).

São diversas as dimensões do mundo contemporâneo e global que se mesclam ao fenômeno religioso, auferindo a ele uma projeção para além do subjetivo. A adesão de adeptos às religiões de matriz afro-brasileira, seja em contextos de filiação, seja em panoramas de experiência efêmera, só pode ser compreendida através de uma reflexão sobre os fluxos transnacionais que

\footnotetext{
12 A análise do ritual de iniciação do iaô, no livro Galinha d'Angola (VOGEL; MELLO; BARROS, 2001), revela uma interpretação sobre os aspectos litúrgicos e ritualísticos da ida à missa como um momento de conflito, no qual os adeptos do Candomblé confrontariam a Igreja Católica. Tal perspectiva é fundamental para pensar o conflito como uma dimensão de associação (SIMMEL, 1977), ou seja, de interação entre indivíduos, abstraindo-o de uma valoração, positiva ou negativa.
} 
ligam o Brasil a diferentes países, como demonstrado nas etnografias presentes nesse dossiê.

\section{DIÁSPORAS AFRO-BRASILEIRAS E RECONFIGURAÇÕES DAS LINHAGENS E IDENTIDADES AFRO-DESCENDENTES}

Um desafio se coloca ao se tentar entender como as religiões afro-brasileiras são recebidas em regiões onde são tão pouco conhecidas, como no contexto europeu, por exemplo. Quem parte do pressuposto que essas sociedades se modernizaram não pode esquecer que esse processo não apagou certas expressões de religiosidade. Assim, a crença em uma variedade de seres espirituais (santos, entidades, bruxas, duendes etc.) que podem interferir na vida das pessoas é algo presente em muitos contextos, fazendo com que as práticas "exóticas" das religiões afro-brasileiras sejam recepcionadas como crenças que valorizam uma relação direta entre os seres espirituais e os indivíduos.

Autores como Bahia (2014, 2015a, 2015b), Capone (2001/2002; 2011), Corrêa (2016), Frigerio (2004; 2013), Guillot (2009, 2012), Oro (1998), Pordeus Júnior (2000, 2009), Saraiva (2010, 2013) e Teisenhoffer (2007) têm buscado compreender os processos de expansão de fronteiras das religiões afro-brasileiras para outros países da América do Sul e Europa, onde existe uma presença marcante do catolicismo e do protestantismo.

Conforme vimos, esses processos estão (em alguns casos) e não estão imbricados aos processos migratórios de brasileiros, que ocorreram a partir da década de 1970 para países do norte global.

Embora o conceito de diáspora seja, para alguns autores, um dos elementos para a compreensão das novas formas de viver dos imigrantes num mundo globalizado. No caso da expansão das religiões afro-brasileiras, é preciso destacar que não há vinculação constante ao processo de diáspora africana como uma ocorrência dramática e histórica para os africanos, provocada pelas perspectivas de submissão a um projeto político-econômico escravocrata (HALL, 2003). 
Nota-se ênfase a outra perspectiva, que associa a matriz africana como referência simbólica de uma ancestralidade e uma identidade política - negritude que é transmitida a partir de uma experiência muito específica: o processo de reinvenção das religiões africanas que se dá no Brasil, que pressupõe encontros e confrontos entre as diversas etnias e seus saberes ancestrais e religiosos, num contexto político de perseguição a essas práticas, de um lado, e de estímulo à mestiçagem, de outro, como parte de uma política de embranquecimento da população. Ao contrário do que se diz no senso comum, não se trata de tudo junto e misturado, mas de uma complexa cena de ora misturado, ora junto, ora separado ${ }^{13}$. As religiões afro-brasileiras se constituíram, portanto, em trânsito entre mundos em conflito explícito e essa marca muitas vezes é oculta das narrativas, o que tem consequências sobre o tipo de racismo ${ }^{14}$ que se manifesta neste caso.

Tölölyan argumenta que o domínio semântico do termo diáspora pode ser compreendido "com termos como migrantes, expatriado, refugiado, trabalhador estrangeiro, exílio, comunidade ultramarina e comunidade étnica e que as diásporas tinham se tornado 'as comunidades exemplares' do momento transnacional” (TÖLÖLYAN, 2017, p. 23). No entanto, o conceito de diáspora, para o autor, deve apresentar formas mais definidas e estar associada a instituições e práticas sociais. $\mathrm{O}$ autor conclui que "diásporas são uma categoria especial de dispersão etnicizada” (TÖLÖLYAN, 2017, p. 28).

Outro autor que discute o conceito de diáspora é Cohen $(1997,2008)$, considerando a referência aos processos históricos, que são orientados por uma memória coletiva, um mito sobre a terra de origem, uma forte consciência grupal étnica baseada num sentido de diferença, uma história comum e uma crença de um destino comum. Salientamos que Cohen discute as dificuldades de se construir um conceito de diáspora pela imputação de características típicas, ao misturar autodefinições de grupo a processos históricos, mas ele

\footnotetext{
13 Podemos pensar em alguns exemplos vinculados aos rituais, que ora são feitos em yorubá, ora em português, as formas como são tratadas as hierarquias nos terreiros (ALMEIDA, 2019).

${ }_{14}$ Vale lembrar Foucault (2010), que explica porque o racismo é necessário ao Estado porque funciona como uma estratégia de exercício do poder sobre o corpo social, que introduz como tecnologia de poder o exercício do "direito de matar" aqueles que forem considerados "impuros", dando fundamento político aos genocídios.
} 
mesmo não analisa as características específicas que resultam das diferentes estratégias de integração de acordo com o tipo de relação com a sociedade local.

Pensamos que a diáspora não deve ser analisada fora de contextos sócio-históricos definidos, pois são os contextos sócio-históricos que permitem a compreensão das relações complexas entre as dimensões do global e local e a sua a permanente significação e ressignificação, a partir das condições locais de cada comunidade, de discursos e práticas geradas em outros contextos.

Alejandro Frigerio (2004), pensando o processo de transnacionalização das religiões afro-brasileiras para o Cone Sul, formula os conceitos de primeira e segunda diásporas religiosas. $\mathrm{O}$ autor argumenta que é necessário distinguir os fluxos transnacionais das religiões afro-americanas no que ele conceitua de primeira e segunda diásporas religiosas, com o intuito de compreender o panorama cada vez mais complexo produzido pelo deslocamento espacial das religiões afro-americanas e sua adoção por um universo de praticantes progressivamente variado.

Para Frigerio (2004), a primeira diáspora seria o deslocamento das religiões africanas para países da América, através do comércio de pessoas escravizadas para o Novo Mundo, fato esse que propiciou a constituição de uma variedade de novos cultos, que englobam o Candomblé do Brasil, o Vodu haitiano e a Santeria cubana, entre outros. Assim, embora esses novos cultos tenham se desenvolvido em cidades e regiões diferentes, trazem consigo semelhanças suficientes de origem, o que garante ao autor a possibilidade de designar esse processo como a primeira diáspora religiosa. Já a segunda diáspora ocorreu entre os cultos afro-americanos constituídos pela primeira diáspora para outras regiões no mundo.

O fluxo das religiões afro-brasileiras para Europa e América do Norte se interligaria, portanto, na perspectiva de um processo de segunda diáspora religiosa formulado por Frigerio (2004). Assim, o aspecto sociologicamente mais relevante do deslocamento espacial que justifica sua distinção entre os conceitos de primeira e segunda diásporas religiosas são as formas de legitimação social adquiridas ao longo do tempo no campo religioso. Enquanto as religiões afro-americanas da primeira diáspora tiveram o seu reconhecimento 
como patrimônio cultural e espiritual ratificados como legítimo após uma longa luta dos seus adeptos contra religiões hegemônicas, tal como o catolicismo, as religiões afro-americanas, no contexto da segunda diáspora, precisam criar novas narrativas de pertencimento nacional que justifiquem sua legitimação no campo religioso.

Frigerio (2004) argumenta que a legitimação das religiões afro-americanas, na primeira diáspora, ocorreu apoiada numa identidade nacional ou regional, vinculada a uma herança étnica ou racial. Na segunda diáspora, o processo tornar-se-ia mais complexo, pois, por não deter uma característica de religião mundial como o cristianismo, budismo ou islamismo -, as religiões afro-americanas encontrariam dificuldades em se legitimar num novo contexto religioso. O fato de a prática ser realizada por pessoas que não compartilham da mesma origem nacional ou regional e nem pertencem ao mesmo grupo étnico que lhes deu origem recorrentemente colocaria em dúvida a legitimidade desses indivíduos como praticantes dessas religiões.

Assim, uma das questões propostas pelo autor seria identificar quais processos são acionados pelos praticantes das religiões afro-brasileiras para se legitimar no campo religioso a partir do conceito de "carreira religiosa", enfatizando que os indivíduos não realizam um movimento único de conversão às religiões afro-americanas, mas empreendem múltiplos engajamentos, em diferentes variações destas, sofrendo mudanças na sua identidade pessoal e social, posteriormente assumindo uma nova identidade nas comunidades religiosas em que tomam parte. Neste sentido, o "africanus sum" (BASTIDE, 1971) ${ }^{15}$, ou seja, na medida em que o processo iniciático se dá, o praticante que incorpora esses valores se relaciona com a África, na medida em que um novo sujeito religioso se cria, renasce juntamente com a sua entrada nas religiões afro brasileiras. Como se dará essa construção tendo um cenário múltiplo, de diferentes matizes com europeus brancos, negros e outros matizes e de diferentes contextos e outros grupos migratórios? Como este neófito se verá e será visto (ou não) como "africano" ou "afro-descendente? Para alguns quem conheceu o segredo

\footnotetext{
15 Ver nota 13.
} 
do Màrìwo foi escolhido pelos orixás, portanto não pode ser questionado por sua adesão às religiões afro-brasileiras.

Logo, é possível concordar com o autor a respeito da ideia de "carreira religiosa”, que ajudaria a compreender de que modo indivíduos que não têm essas religiões como parte da sua "herança cultural"16 são gradualmente e sequencialmente nelas socializados. Como exemplo, podemos pensar no caso de Pierre Verger, que foi renomeado pelos orixás como Fatumbi. Essa configuração das religiões afro-brasileiras revela não só sua perspectiva multicultural, já que o Candomblé é considerado um fruto das interlocuções entre Brasil e África, mas também aponta para articulações políticas e sociais de múltiplas pertenças, que nega a possibilidade de um retorno a uma tradição pura, muito embora essa narrativa se constitua como um desejo, uma expectativa. Há que se salientar que essa perspectiva - pureza - traz em si uma armadilha: "o risco de perpetuar as ideologias que colocam os povos negros como culturalmente inferiores aos brancos" (RODRIGUES, 2012, p. 8).

\section{ENTRECRUZAMENTOS ENTRE CRENÇAS E PRÁTICAS MÁGICO-RELIGIOSAS}

Práticas, objetos e ideias religiosas atuam configurando fluxos constantes que dão origem às redes transnacionais no campo religioso, ainda mais se levarmos em consideração que o mundo cada vez mais está interconectado por redes de informação, transportes mais eficientes e rápidos que proporcionam aportar em outras cidades, países, ou seja, atravessar novas fronteiras. Tendo isso em vista, "torna-se cada vez mais acessível a pessoas localizadas em diferentes partes do mundo o acesso a informações e relatos de experiências das mais diversas" (Meirelles, 2012, p. 306), incluindo novas experiências religiosas.

\footnotetext{
${ }^{16}$ Cabe frisar que a ideia de "herança cultural" é trazida pelo autor como parte um discurso que evoca a incompatibilidade entre certas práticas religiosas e determinados grupos nacionais ou étnicos diante de uma suposta ausência de tradição.
} 
Tomando como entendimento o mesmo adotado por Oro (1998), inspirado pela proposição de Badie e Smouths (1992) sobre a ideia de transnacionalização, é viável constatar que a relação entre pessoas e bens materiais passa a ser constituída no espaço mundial para além dos limites do Estado-Nação, e que se materializa fugindo, de forma parcial, do controle ou da ação mediadora dos Estados. Logo, é possível considerar que é nessa acepção que devem ser observadas as novas relações no campo religioso que são apresentadas em diferentes contextos que serão analisados nesse dossiê.

Welz (2004), em seu artigo "Multiple modernities: the transnationalization of cultures", discorre sobre a questão da transnacionalização das culturas, afirmando que autores como Hannerz (1996), Ong (1999) e Appadurai (1996) a utilizam numa perspectiva antropológica, com o intuito de capturar os processos culturais que fluem através das fronteiras dos Estados-Nação. Assim, o "transnacional" tem se tornado um termo habitual na Antropologia para descrever qualquer fenômeno cultural que se estende para além, ou transversalmente, dos limites do Estado e é um efeito da difusão ou dispersão de pessoas, ideias e artefatos, através de grandes distâncias. Muitas vezes, nesse processo de transnacionalização, pessoas, ideias e artefatos deixam de ser identificados com os seus próprios locais de origem. A transnacionalização é compreendida como uma forma de interligação cultural e de mobilidade através do espaço, ou seja, como qualquer fenômeno cultural que se estende para além dos limites do Estado-Nação.

Os antropólogos citados anteriormente distinguem o processo transnacional da globalização. Por um lado, a globalização é definida a partir da incorporação de processos políticos e econômicos, cujos protagonistas são corporações multinacionais, governos nacionais e organizações supranacionais envolvidos em uma escala mundial. Por outro lado, o uso do termo "transnacional" chama a atenção para o crescente envolvimento de outros tipos de atores-indivíduos, grupos de parentesco, grupos étnicos, empresas, movimentos sociais etc., em atividades e relações que transcendem as fronteiras nacionais (WELZ, 2004). Ong (1999, p. 4, por outro lado afirma que a transnacionalidade é o termo mais adequado para simbolizar a "condição de interligação cultural e da mobilidade através do espaço", que foi intensificada sob o capitalismo tardio. 
Em outras palavras, podemos observar a partir dos artigos presentes no dossiê que existe uma fluidez das práticas culturais e religiosas entre e para além dos limites preconizados pelo Estado-Nação, que segundo Csordas (2009) corresponde a um processo de migração, mobilidade, mídia e missionarização, compondo o que ele designa de "transnacionalização transcendente". Conforme esse autor, uma religião seria passível de um processo de transnacionalização quando fosse capaz de difundir seus princípios, premissas e promessas religiosas a contextos distintos daqueles nos quais foram gerados.

Desta forma, o termo "transnacionalização transcendente", proposto por Csordas, se refere ao processo de transnacionalização observado e ao revés da inicial expansão das grandes religiões monoteístas, impulsionadas pelos Estados nacionais imperialistas. Atualmente, há migrações de sul a norte, do Oriente para o Ocidente, das periferias para os centros metropolitanos, das culturas subalternas para as religiões hegemônicas, o que nos faz crer que aos poucos se constrói uma nova geografia religiosa no mundo, com grande impacto no deslocamento de práticas religiosas profundamente ligadas a suas tradições, territórios e grupos sociais específicos e notadamente nacionais. Tradições migram do sul ao norte, da periferia ao centro, do Oriente ao Ocidente do mapa-múndi e paradoxalmente reelaboram tanto os localismos, reivindicando uma identidade étnico-nacional, quanto os cosmopolitismos, que forjam culturas híbridas.

Appadurai (1996, p. 176) também salienta a importância de produtos de massa mediados pela comunicação, rádio, televisão, vídeos de música e filmes que, em conjunto com processos de migração, "vêm à tona como forças que parecem impulsionar (e algumas vezes obrigam) o trabalho da imaginação".

O imaginário referente ao Brasil do Carnaval, do samba, da capoeira e das manifestações religiosas exóticas foi, e ainda é, bastante difundido na Europa e Estados Unidos como um produto turístico. Observamos nos artigos aqui expostos que não apenas os fluxos migratórios influenciaram a adesão a novas identidades religiosas, como também os meios de comunicação e a própria imaginação. Todas atuando como ações necessárias para a constituição dos novos espaços de vida vinculados às suas práticas religiosas. Tal processo pode 
ser verificado no contexto da transnacionalização das religiões afro-brasileiras para Portugal, Alemanha, Itália e Estados Unidos.

A partir dos anos de 1960, as religiões afro-brasileiras se expandiram para Uruguai, Paraguai, Venezuela e Argentina. A partir da década de 1970, atravessou o Atlântico e expandiu-se para Portugal (BONIOLO, 2019; CORRÊA, 2016; GUILLOT, 2009, 2012; MIRANDA; CORRÊA, 2019; PORDEUS JÚNIOR, 2000; SARAIVA, 2010). Está agora nos Estados Unidos, Espanha, Reino Unido, Bélgica, Itália, França (CAPONE, 2001/2002, 2011; TEISENHOFFER, 2007), Alemanha (BAHIA, 2015a, 2015b, 2016; SILVA, 2014), Áustria, Suíça, Rússia e Japão (ARAKAKI, 2013).

\section{A EXPERIÊNCIA ETNOGRÁFICA EM CAMPOS MULTISSITUADOS}

Os artigos presentes no dossiê também buscaram debater, analisar e utilizar novas ferramentas metodológicas mais adequadas para a construção de um conhecimento sobre práticas culturais e, ao mesmo tempo, capazes de propiciar um conhecimento dos fenômenos sociais contemporâneos.

Observamos nos diferentes artigos que os autores buscaram dialogar com a concepção do método de pesquisa proposto por Marcus (1995) - realizar uma etnografia multissituada.

Para esse autor, a pesquisa multissituada está construída ao redor de cadeias, caminhos, fios, conjunções e justaposições de lugares nos quais o etnógrafo estabelece formas de presença física, com uma lógica explícita e situada de associações ou de conexões entre os locais que, de fato, definem o argumento da etnografia. Isso, porém, não significa que todos os locais precisem ser tratados com o mesmo conjunto de práticas de trabalho de campo, sendo investigados na mesma intensidade, pois a etnografia multissituada é inevitavelmente o produto de bases de conhecimento de várias intensidades e qualidades.

Os processos de construção dos objetos de pesquisa jogam, dessa forma, com complexas variáveis: as identidades e os locais. Contudo, isso não implica 
negar certa individualidade, mas considerar seu caráter plural. Essa individualidade terá lugar em contextos multifacetados, centrando o interesse nos lugares onde se manifesta o objeto de pesquisa. Esse ponto de vista dá lugar a muitas maneiras de examinar a vida cotidiana dos indivíduos. Sem ser reduzida ao local ou global, essa perspectiva permite, pela multiplicidade que oferece, aceitar que o que antigamente denominamos de "nativos" tenha a possibilidade de situar-se em diferentes locais, ter distintos papéis e pertencer a diferentes categorias (MARCUS, 1995).

Marcus conceitua a etnografia multissituada segundo uma perspectiva peculiar de construção de uma ordem social mais ampla, com o intuito de superar as dicotomias clássicas estabelecidas das formas convencionais, tal como a ideia de observação participante, que pressupunha uma imersão profunda junto a um grupo, e propor uma percepção de um contexto particular de pesquisa durante o qual os processos de circulação dos significados culturais, objetos e identidades se dá a partir da experiência etnográfica do pesquisador.

Contra a dimensão holística da cultura, a reformulação proposta por Marcus prioriza a dimensão analítica da investigação, mais que a produção de uma descrição completa de um único fenômeno. De fato, as características desses métodos influenciam diretamente na produção e construção dos dados, sem dúvida, de qualidade e de intensidade variável.

A partir de perspectivas etnográficas distintas, os artigos desse dossiê exploram, analisam e debatem as estratégias, os conflitos e as consequências da mundialização e transnacionalização das religiões afro-brasileiras para diferentes contextos, tendo em consideração os processos culturais e políticos que decorrem da expansão das fronteiras nacionais. Interessou-nos compreender as especificidades das práticas religiosas de matriz afro-brasileira em seu processo de transnacionalização em face de identidades, que se construíram por meio de laços socioculturais históricos com o Brasil.

O dossiê reuniu artigos, aprovados após submissão às cegas de pareceristas externos, resultado de pesquisas etnográficas em diferentes contextos nacionais, que exploraram: as percepções e sentidos das religiosidades afro-brasileiras; as adaptações das manifestações das religiões afro-brasileiras em 
contextos transnacionais; as distintas dimensões dos rituais e das manifestações artístico-culturais (música, dança, Capoeira etc.); o papel da tecnologia e das redes sociais na expansão das fronteiras afro-religiosas; a (re)criação de relações sociais; as legislações e a reivindicação de direitos de liberdade religiosa; os conflitos decorrentes da realização de ritos; e as políticas públicas de proteção ao ambiente. Buscamos selecionar artigos de diferentes instituições e contextos etnográficos com o intuito de apresentar uma diversidade de campos e temas a serem debatidos nesse dossiê.

Iniciamos o dossiê com o artigo "Quando a 'Avamunha' não bate: o conflito como aspecto estruturante do Candomblé em Portugal" de João Ferreira Dias, pesquisador integrado do Centro de Estudos Internacionais do Instituto Universitário de Lisboa e do Centro de História da Universidade de Lisboa. Ele analisa os conflitos como força estruturante das religiões afro-brasileiras do campo religioso português, cujas dinâmicas revelam a existência de alianças feitas e refeitas, com base em critérios de nacionalidade e sexualidade e demandas do mercado religioso. Para o autor, o conflito faz parte da construção do processo de transnacionalização do Candomblé para Portugal, onde acarretou um processo de ressignificação religiosa que vem sendo enfatizado pela literatura antropológica dedicada ao tema. Neste artigo, entretanto, o autor percorre um caminho diferente do apresentado pela literatura dedicada ao tema a qual enfatiza, essencialmente, os processos de adaptação simbólica e ritual de tais religiões a Portugal, enfocando os diálogos entre referenciais católicos e afro-brasileiros. Nesse sentido, a prioridade da análise recai sobre a dimensão sociológica do Candomblé por via das relações entre membros da comunidade candomblecista, as quais assentam, sobretudo, numa lógica de conflito, segundo três vetores: sexualidade, nacionalidade e mercado religioso.

Em seguida temos o artigo "Entre pernadas e possessões: encruzilhadas da umbanda e da capoeira nos espaços circulares afro-lusófonos" de Ricardo Carvalho Nascimento, Professor do Instituto de Humanidades da Universidade da Integração Internacional e da Lusofonia Afro-Brasileira. O autor também se debruçou sobre o processo de transnacionalização das práticas das religiões afro-brasileiras e a capoeira. Sua análise buscou compreender como as 
lideranças empreenderam estratégias de fixação da Umbanda e capoeira na sociedade portuguesa. $\mathrm{O}$ artigo problematiza a trajetória partilhada das religiões afro-brasileiras e da Capoeira no contexto português, a partir da concepção de um conjunto existencial de fatores sociais, conjunturais e históricos da formação do atlântico negro lusófono, que beneficiaram a mobilidade e inserção das duas práticas em território luso. Busca ainda compreender os significados atribuídos pelos integrantes do Grupo Capoeirarte e do templo de Umbanda Atupo, como se constitui um empreendimento das culturas negras no Atlântico, a partir dos conceitos de contracolonização e circularidade.

O artigo da Tatiana Golfetto, doutora em História, Antropologia e Religião pela Universidade de Roma Sapienza, "O candomblé na Europa: fluxos e refluxos entre Brasil, Itália e Portugal”, irá discorrer como os processos de transnacionalização das religiões afro-brasileiras se interconectam nesses três países a partir da etnografia realizada com adeptos de diferentes terreiros vinculados a uma mesma linhagem religiosa brasileira que se encontram no Brasil, na Itália e em Portugal. Tendo como ponto de partida o conceito de "campo social transnacional", para evidenciar como a circulação e a direção dos fluxos de bens materiais e simbólicos ocorrem entre esses países, revela, assim, as dinâmicas e estratégias dos seus integrantes. Além disso, apresenta as diferentes percepções dos adeptos das religiões afro-brasileiras em relação à interação com os irmãos de santo de nacionalidades diferentes, percepções essas decorrentes das estadias e dos períodos de convivência, a fim de compreender os modos como esses integrantes constroem diferenças e semelhanças entre eles. A autora busca compreender as estratégias de expansão, as apropriações e as ressignificações locais, onde é possível considerar a transnacionalização também sob o aspecto da criação de redes de interações sociais que ligam contextos ou países diferentes. $\mathrm{O}$ artigo procura construir uma reflexão sobre o aspecto relacional da transnacionalização, ou seja, a análise das interações que se manifestam em comunidades de Candomblé que ultrapassam as fronteiras nacionais e que ligam pessoas que se encontram em países diferentes.

Giovanna Capponi, doutora em Antropologia pela Universidade de Roehampton (Londres) e atualmente pesquisadora de Pós-Doutorado do 
Museu do Quai Branly (Paris), no artigo "Candomblé rituals and food practices in Italy and Brazil: an ethnographic comparison", analisa a relação entre as práticas alimentares, a preparação de oferendas rituais do Candomblé e a realização de rituais, a partir de relatos sobre o assunto na Itália e no Brasil. A autora se empenha em compreender como os religiosos italianos percebem diferentes aspectos da preparação das oferendas rituais e que valores estão em jogo na cozinha e no consumo desses alimentos e oferendas. Descrevendo, inclusive como a memória e a dimensão sensorial são essenciais para construir uma nova ideia de familiaridade no caso italiano para aprender as técnicas de preparação dentro da prática ritual. Nos dois contextos etnográficos, as diferentes memórias e estruturas sociais mediam práticas e inovações alimentares.

Referindo-se ao contexto europeu, Joana Bahia, Professora titular do departamento de Ciências Humanas e da Pós-Graduação em História Social da UERJ, no artigo "Europa 'underground': enverdecimento do ser, Reforma da Vida, bruxarias e outros modos de pensar o espiritual", explora o modo como o movimento da Reforma da Vida colaborou para a construção de uma espiritualidade e novos modos de pensar o sujeito, que forjaram os elementos socioculturais de receptividade às religiosidades afro-brasileiras não apenas na Alemanha, mas em grande parte do contexto europeu, trazendo também problemas para a transnacionalização religiosa, em que ressurgem práticas do veganismo e outros modos de lidar com a construção religiosa do sujeito europeu sob grande influência das práticas espiritualistas e da chamada Nova Era.

A autora parte da ideia que sempre existiu uma "Europa 'underground', em que as práticas mágicas e os misticismos estavam sempre presentes no imaginário popular e em sua própria história, havendo a possibilidade de reviver esses paganismos com a entrada recente de novas religiosidades". Bahia conclui que, o misticismo europeu, presente na ideia do movimento romântico alemão, agregou outros conhecimentos religiosos ao universo afro-religioso.

O último artigo do dossiê, “Àwọn İyà Awo, as senhoras do segredo na big apple: mulheres nas práticas de Candomblé na cidade de Nova Iorque (EUA)", de Marcelo Máximo Niel, Doutor em Ciências Sociais pela Unifesp, e Pedro Paulo Gomes Pereira, Professor Livre docente da Unifesp e Coordenador do 
Quereres, analisam a transnacionalização das religiões afro-brasileiras no contexto norte-americano. As etnografias realizadas em diferentes terreiros de Candomblé na cidade de Nova Iorque expõem as trajetórias de três mães de santo brasileiras, que contribuíram para a constituição dessas práticas religiosas no novo contexto transnacional. As narrativas dessas religiosas demonstram como elas "reinventam o Candomblé, articulando segredos, permissões e traduções das suas práticas, fazendo, paradoxalmente, com que ele permaneça o mesmo, contribuindo para a propagação e para o estabelecimento da religião nesse novo lugar. Um dos pontos importantes encontrados nessa reinvenção foi à mudança no aspecto hierárquico, uma vez que as mães de santo adotam um sistema de interação mais horizontal com seus adeptos e clientes em contraposição ao modelo mais verticalizado, como o prevalente nos terreiros brasileiros".

\section{CONSIDERAÇÕES FINAIS}

Os artigos presentes no dossiê buscaram apresentar a partir de etnografias as mais diversas experiências das religiosidades afro-brasileiras em contextos transnacionais. As etnografias desvelam os processos de implantação e fixação dessa nova religiosidade.

Observamos que a transnacionalização das religioes afro-brasileiras estão vinculadas a diferentes fatores, tais como: processos migratórios, rede de comunicações, turismo religioso. Os artigos apresentam os diferentes contextos sócio-históricos que as religiões afro-brasileiras se fixaram nos países como Itália, Alemanha, Portugal e Estados Unidos e a necessidade de aquisição de novas plasticidades para se acomodar e se reproduzir no campo religioso dessas nações.

Podemos observar como novos usos e maneiras das práticas religiosas ora se aproximam e ora se afastam do Brasil como criador ou centro da religião, tornando o panorama transnacional muito mais complexo e contraditório. Um exemplo disso é a incorporação de comidas italianas aos rituais do Candomble na Itália como 
forma de reverenciar a uma ancestralidade, conforme demonstra Capponi no seu artigo deste número. No estudo de Arakaki (2013), vemos que os Exus trabalham juntos aos samurais, reconfigurando o panteão dos espíritos de defesa e proteção na Umbanda praticada no Japão.

Nesse sentido, estudar a transnacionalização das religiões afro-brasileiras torna-se relevante para entender o papel do Brasil nessa nova cartografia religiosa global, além de permitir compreender as diferentes maneiras pelas quais a espiritualidade é definida a partir de uma plasticidade adaptativa que gera novas formas de se pensar e viver o fenômeno religioso.

Observar as religiões afro-brasileiras nesses contextos permitiu compreender como essas práticas religiosas conectam diferentes fenômenos sociais (psicoterapias, natureza, ciência e religião), resultando em diversas combinações, permitindo que europeus vivenciem uma nova experiência religiosa.

Além disso, podemos observar como os símbolos religiosos se apropriam dos espaços urbanos de muitas cidades do mundo, criando novas paisagens e novas comunidades imaginadas. A exemplo de Mãe Dalva de Oxum que usa o muro de Berlim (Berliner Mauer) como metáfora tanto para reinterpretar o sentido do muro para lidar com o mundo dos Eguns ${ }^{17}$, neste caso os próprios alemães que morreram atravessando-o, e que foram esquecidos pela história, mas que no Candomblé devem ser lembrados e reverenciados, quanto para lidar com um marcador da identidade brasileira em seus momentos distintos de migração para Alemanha. Neste último aspecto (BAHIA, 2012, 2013, 2014, 2015b), a vivência de Mãe Dalva em Berlim é marcada por uma cidade dividida, difícil de se viver para muitos brasileiros que chegaram antes da sua construção ${ }^{18}$. O período anterior à queda foi, segundo vários brasileiros, um

\footnotetext{
${ }^{17}$ Mãe Dalva de Oxum e outros pais de santo entrevistados consideram Berlim uma cidade de Exu, por ser um lugar liminar da história, um lugar difícil de viver, em que é necessária a capacidade de mediação (recriação simultânea da ordem e desordem/transitoriedade/flexibilização) do referido orixá (BAHIA, 2014). Essa mãe de santo usou o muro por muitos anos como local para realização de despachos, pois o considera um cemitério.

18 Não obstante os brasileiros considerarem a existência do muro algo complicado no seu cotidiano, os estudos acadêmicos indicam a existência de pouco preconceito contra os estrangeiros antes da queda do muro. O período que se seguiu à queda do Muro de Berlim é considerado o período de maior ódio contra os estrangeiros (BEHRENDS, 2003).
} 
período difícil para os emigrantes porque Berlim era considerada por eles uma cidade racista e discriminatória.

Novas religiosidades têm permitido alterar principalmente os centros urbanos, suas antigas configurações espaciais, transformando a paisagem urbana, o cotidiano do viver na cidade com a presença de práticas culturais multiétnicas.

Além desses debates, este número da Antropolítica traz cinco artigos com temática livre, oriundos do fluxo contínuo da revista e um artigo na seção "Olhares Cruzados". Iniciamos com o artigo "Pertencimento étnico e compromissos morais: curdos em diáspora na Dinamarca e os direitos humanos no Curdistão", de Tiago Duarte Dias. A partir de análise etnográfica, o texto discute a relação entre a população curda em situação de diáspora e aquela estabelecida em território curdo, focando os laços sociais, políticos e culturais, que mantêm e constroem entre si. $O$ autor argumenta que esses laços se fundamentam numa identidade comum como "povo", em relação de alteridade com um "outro". Em particular, o artigo traz para a reflexão como esses laços são construídos em torno da categoria "direitos humanos", buscando mobilizar outros grupos em defesa dos curdos como "minoria étnica" diante do que seria uma "tentativa de genocídio" do povo curdo.

Em seguida, em continuidade com a linha de pesquisa sobre identidade e Oriente Médio, o artigo de Bruno Ferraz Bartel, "O santo e a cura: performances e subjetividades no mausoléu de Sidi 'Ali bem Hamdouche, Marrocos", descreve e analisa as práticas de cura dos fuqaha (especialistas religiosos islâmicos). Para além da dimensão ritual (nos seus planos emotivo, sensorial e cognitivo), o artigo destaca o papel dos objetos, bem como das concepções femininas sobre essas práticas. Assim, propõe uma discussão sobre a própria concepção de "tradição", mostrando como ela é um campo em disputa entre diferentes atores e moralidades. 
Já o terceiro artigo, intitulado "As indenizações como política de direitos humanos e de justiça social no Brasil Contemporâneo", de autoria de Paula Lacerda, propõe analisar as indenizações como parte de um espectro mais amplo de políticas de reparação. A partir da descrição e análise de quatro casos de indenizações financeiras por parte do Estado brasileiro diante de situações de violações de direitos, o artigo afirma que essas práticas são mínimas, mas, ao mesmo tempo, operam um papel importante no reconhecimento institucional do dano produzido e da identidade da vítima, inserindo-se, nesse sentido, no campo dos direitos humanos e da justiça social. Em seguida, apresentamos o artigo "Comunidades ribeirinhas na Amazônia: perdidas no espaço e no tempo dos grandes projetos hidrelétricos", de co-autoria de Luis Fernando Novoa Garzon e Daniele Severo da Silva. A partir do acompanhamento do processo de implementação das Usinas Hidrelétricas Santo Antônio e Jirau no rio Madeira, em Rondônia, o artigo apresenta e analisa os caminhos institucionais e discursivos adotados na expansão dessa fronteira. Privilegiando o ponto de vista e a interlocução com os moradores, os autores descrevem como, a partir das sucessivas desterritorializações impostas, a comunidade desenvolve estratégias de sobrevivência econômica, social e cultural.

Por fim, o artigo de Pedro Heitor Barros Geraldo e Betânia de Oliveira Almeida de Andrade, “Esperteza' e 'bom comportamento' na execução penal”, a partir de pesquisa empírica em uma Unidade Prisional Feminina do Estado do Rio de Janeiro, analisa, em perspectiva interdisciplinar, como a decisão judicial sobre o cumprimento da pena de privação de liberdade responde a critérios arbitrários e subjetivos que afetam negativamente os direitos e garantias das pessoas potencialmente beneficiárias.

Por sua parte, a seção "Olhares Cruzados" da Antropolítica tem como proposta publicar artigos que reflitam sobre as várias dimensões que envolvem o fazer antropológico, priorizando a discussão sobre a perspectiva internacional, transnacional e/ou comparada na experiência do pesquisador. Nessenúmero, publicamos o artigo "A hospitalidade em Paris eBuenos Aires: seguindo consumidores de vinhos para além do Rio de Janeiro", de Luciana Freire Murgel. A autora relata suas experiências durante o trabalho de campo envolvendo três países: Brasil, França e Argentina. A reflexão conduz a traçar uma ponte entre a 
dimensão metodológica da pesquisa, envolvendo o método de comparação por contraste e a experiência de estranhamento do familiar, com a constituição dos próprios dados de pesquisa, demonstrando como "a cultura do vinho" no Brasil também opera através da "hospitalidade" da figura do estrangeiro. Por último, esse número conta com a resenha, de autoria de Luiz Gustavo Bonatto Rufino, sobre o livro "The death of expertise: the campaign against established knowledge and why it matters", de Tom Nichols. Editado e publicado pela Oxford University Press, em 2017, o livro trata de um tema extremamente atual qual sejam diversos discursos e práticas contemporâneos de ataque e rejeição da ciência, da racionalidade e do senso crítico, como fundamentos da civilização moderna.

A foto de capa foi cedida generosamente pelo fotógrafo brasileiro Fernando Miceli. Ela lança um olhar sobre o fenômeno da expansão religiosa ao fotografar a Lavagem do Dom feita, no mês de janeiro, pelos adeptos do Candomblé na cidade de Berlim, Alemanha. Lembramos que no mês de janeiro, os terreiros brasileiros comemoram as águas de Oxalá, e no Bonfim é realizada uma das maiores festas de santo em Salvador, Bahia. Neste sentido, o modo de se sentir parte desse Atlântico Negro é revivido com novas conexões globais, que não necessariamente cumprem a lógica estritamente do "passado colonial", pois Alemanha e Brasil não estão conectados deste modo, e ainda assim criam uma "imaginação transafricana", muito além da "perpetuação histórica das comunidades diaspóricas".

\section{REFERÊNCIAS BIBLIOGRÁFICAS}

1. ALMEIDA, Rosiane Rodrigues de. A luta por um modo de vida: as narrativas e estratégias de enfrentamento ao racismo religioso dos membros do FONSANPOTMA. 2019. Tese (Doutorado em Antropologia) Universidade Federal Fluminense, Niterói, 2019.

2. APPADURAI, Arjun. Modernity at large: cultural dimensions of globalization. Minneapolis/London: University of Minnesota Press, 1996. p. 172-179.

3. ARAKAKI, Ushi. Japanese brazilians among pretos velhos, caboclo, buddhist monks and samurais: an ethnographic study of Umbanda in Japan. In: ROCHA, 
Cristina; VÁSQUEZ, Manuel A. The diaspora of brazilian religions. Leiden: Brill, 2013. p. 249-270.

4. ARGYRIADIS, Kali; CAPONE, Stefania. La religion des orisha: un champ social transnational en pleine recomposition. Paris: Hermann, 2011.

5. ASSIS, Gláucia de Oliveira. Os pequenos pontos de partida: as mobilidades contemporâneas rumo à Europa nesse início de séc. XXI. In: SIMPÓSIO NACIONAL DE HiSTÓRIA, 27., 2013, Natal. Anais [...]. Natal: Universidade do Rio Grande do Norte, 2013. p. 1-12.

6. ASSIS, Gláucia de Oliveira; MARTINS, Tiago. As representações sobre os novos imigrantes brasileiros rumo à Europa: gênero, etnicidade e preconceito. In: REUNIÃO BRASILEIRA DE ANTROPOLOGIA, 26., 2010, Porto Seguro. Anais [...]. Porto Seguro: Associação Brasileira de Antropologia, 2010a. Mimeografado.

7. ASSIS, Gláucia de Oliveira; MARTINS, Tiago W. Criminalização das migrações contemporâneas: as brasileiras na mídia europeia no período entre 2003 e 2009. In:SEMINÁRIO INTERNACIONAL FAZENDO GÊNERO, 9., 2010, Florianópolis. Anais [...]. Florianópolis: Universidade de Santa Catarina, $2010 \mathrm{~b}$.

8. BADIE, Bertrand; SMOUTS, Marie-Claude. Le retournement du monde: sociologie de la scène internationale. Paris: Presse de la Fondation Nationale des Sciences Politiques \& Dallorz, 1992.

9. BAHIA, Joana. A descoberta de Putamagal pelo caboclo Pena Dourada. In: RODRIGUES, Donizete; ORO, Ari Pedro (org.). Transnacionalização religiosa: religiões em movimento. Porto Alegre: CirKula, 2015a.

10. BAHIA, Joana. As religiões afro-brasileiras em terras alemãs e suiças. Lisboa: Universidade de Lisboa, 2013. 21 p. (Working paper). Disponível em: https:// bit.ly/393XGQg. Acesso em: 17 mar. 2020.

11. BAHIA, Joana. De Miguel Couto a Berlim: a presença do Candomblé brasileiro em terras alemãs. In: PEREIRA, Glória Maria Santiago; PEREIRA, José Ribamar Sousa. (org.). Migração e globalização: um olhar interdisciplinar. Curitiba: CRV, 2012. p. 223-244.

12. BAHIA, Joana. Deus tem passaporte? Os delicados fios que tecem as relações entre socialização religiosa, educação e motivações migratórias. In: BAHIA, Joana; SANTOS, Miriam (org.). Um olhar sobre as diferenças: a interface entre projetos educativos e migratórios. São Leopoldo: Oikos, 2016. p. 100-127.

13. BAHIA, Joana. E o preto-velho fala alemão: espíritos transnacionais e o campo religioso na Alemanha. Revista del CESLA, Warsaw, n. 18, p. 181-212, $2015 \mathrm{~b}$.

14. BAHIA, Joana. Under the Berlin sky: Candomblé on German shores. Vibrant, Brasília, DF, v. 11. n. 2, p. 326-369, 2014. 
15. BAKHTIN, Mikhail. Problemas da poética de Dostoiévski. Rio de Janeiro: Forense-Universitária, 1981.

16. BASTIDE, Roger. As religiões africanas no Brasil. São Paulo: Edusp, 1971.

17. BASTIDE, Roger. Mémoire collective et sociologie du bricolage. L’Année Sociologique, Paris, v. 21, p. 65-108, 1970.

18. BEHRENDS, Jan C.; LINDENBERG, T.; POUTRUS, P. G. Fremde und Fremd-Sein in der DDR: Zu historischen Ursachen der Fremdenfeindlichkeit in Ostdeutschland. Berlin: Metropol, 2003.

19. BESERRA, Bernadete. Entre as demandas de Deus e as da sobrevivência: os brasileiros adventistas de Chino. Revista Travessia, São Paulo, v. 19, n. 55, p. 17-22, 2006.

20. BONIOLO, Roberta Machado. Em Portugal ninguém nascia Umbandista: a pluralidade religiosa e os conflitos no espaço público envolvendo as práticas religiosas luso-afro-brasileiras. 2019. Tese (Doutorado em Antropologia Social) - Universidade Federal Fluminense, Niterói, 2019.

21. CANCLINI, Nestor García. Culturas híbridas: estratégias para entrar e sair da modernidade. 4. ed. São Paulo: Edusp, 2006.

22. CAPONE, Stefania. La diffusion des religions afro-américaines en Europe. Psychopathologie Africaine, [s. l.], v. 31, n. 1, p. 3-16, 2001/2002.

23. CAPONE, Stefania. Os Yoruba do novo mundo: religião, etnicidade e nacionalismo negro nos Estados Unidos. Rio de Janeiro: Pallas, 2011.

24. COHEN, Robin. Global diaspora: an introduction. Seattle: University of Washington Press, 1997.

25. COHEN, Robin. Sólidas, dúcteis e líquidas: noções em mutação de "lar" e “terra natal” nos estudos da diáspora. Caderno CHR, Salvador, v. 21, n. 54 p. 519-532, 2008.

26. CORRÊA, Aureanice de Mello. Irmandade da Boa Morte como manifestação cultural afro-brasileira: de cultura alternativa à inserção global. 2004. Tese (Doutorado em Geografia) - Universidade Federal do Rio de Janeiro, Rio de Janeiro, 2004.

27. CORRÊA, Roberta de Mello. O Sagrado à porta fechada: (in) visibilidade das religiões de matriz afro-brasileira no campo religioso português. 2016. Tese (Doutorado em Antropologia) - Universidade Federal Fluminense, Niterói, 2016.

28. COSSARD-BINON, Gisèle. Origines lointaines du syncretisme afro-catholique au Brésil et perspectives d’avenir. Afro-Ásia, Salvador, n. 12, p. 161-166, 1976. 
29. CSORDAS, Thomas J. Introduction: modalities of transnational transcendence. In: CSORDAS, Thomas J. (ed.). Transnational transcendence: essays on religion and globalization. Berkeley: University of California Press, 2009. p. 1-29.

30. DROOGERS, André. Syncretism: the problem of definition, the definition of the problem. In: GORT, Jerald D.; VROOM, Hendrik M.; FERNHOUT, Rein; WESSELS, Anton. (ed.). Dialogue and syncretism: an interdisciplinary aproach. Amsterdam: William B. Eerdmans, 1989, p. 7-25.

31. ENGLER, Stephen. Umbanda e a glocalização. Debates do Ner, Porto Alegre, ano 12, n. 20, p. 11-44, 2011.

32. ESPAÇO além Marina Bramovic e o Brasil. Direção de Marco Del Fiol. Produção de Casa Redonda, Yasmin Pinho e Minom Pinho. São Paulo: Governo do Estado de São Paulo, 2016. (86 minutos), color.

33. FERRETTI, Sérgio E. Sincretismo afro-brasileiro e resistência cultural. Horizontes Antropológicos, Porto Alegre, ano 4, n. 8, p. 182-198, 1998.

34. FERRETTI, Sergio. Repensando o sincretismo: estudo sobre a casa das Minas. São Paulo: Edusp, 1995.

35. FOUCAULT, Michel. Em defesa da sociedade. 2. ed. São Paulo: Martins Fontes, 2010.

36. FRIGERIO, Alejandro. A transnacionalização como fluxo religioso na fronteira e como campo social: Umbanda e Batuque na Argentina. Debates do NER, Porto Alegre, ano 14, n. 23, p. 15-57, 2013.

37. FRIGERIO. Alejandro. El futuro de las religiones mágicas en Latinoamérica. Ciencias Sociales y Religión, Porto Alegre, v. 1, n. 1, p. 51-88, 1999.

38. FRIGERIO. Alejandro. Re-africanization in secondary religious diasporas: constructing a world religion. Civilisations, [s. l.], n. 51, p. 39-60, 2004.

39. GIUMBELLI, Emerson. O campo religioso brasileiro em suas configurações. In: SILVEIRA, Emerson José Sena de; SOFIATI, Flávio Munhoz. (org.). Novas leituras do campo religioso brasileiro. São Paulo: Ideias \& Letras, 2014. p. 169-194.

40. GREENFIELD, Sidney M.; DROOGERS, André. (ed.). Reinventing religious: syncretism and transformation in Africa and the Americas. Lanham: Rowman and Littlefield, 2001.

41. GREENFIELD, Sidney M.; DROOGERS, André. Syncretic process and the definition of the new religious. Journal of Contemporary Religion, Abingdon, v. 18, n. 1, p. 25-36, 2003.

42. GREGANICH, Jéssica. Between Brazil and Spain: structure and butinage in the trajectories of Santo Daime and União do Vegetal. In: OOSTERBAHN, Martijn; 
VAN DE KAMP, Linda; BAHIA, Joana (ed.). Global trajectories of brazilian religion: Lusospheres. Londres: Bloomsbury, 2020. p. 135-151.

43. GREGANICH, Jéssica. O axé de Juramidam: a aliança entre o Santo Daime e a Umbanda. Debates do NER, Porto Alegre, ano 12, n. 19, p. 77-106, 2011.

44. GUILLOT, Maïa. Du mythe de l'unité Luso-Afro-Brésilienne: le candomblé et l'umbanda au Portugal. Lusotopie, Provença, v. 16, n. 2, p. 205-219, 2009.

45. GUILLOT, Maïa. Logiques transnationales et stratégies locales: les étapes de lìmplantation des religions afro-brésiliennes au Portugal. Canadian Journal of african Studies, Hoboken, v. 46, n. 3, p. 381-395, 2012.

46. GUILlOT, Maïa; HUET, Juárez Nahayeilli. Dynamiques religieuses et logique marchande dês religions adro-américanes au Mexique et au Portugal. In: ARGYRIADIS, Kali; CAPONE, Stefania; TORRE, Renée de la; MARY, André. (org.). Transnationalisation des religions africaines: Afrique, Europe, Amérique. Paris: Academia-L'Harmattan, 2012.

47. HALL, Stuart. Da diáspora: identidades e mediações culturais. Belo Horizonte: Editora UFMG, 2003.

48. HANNERZ, Ulf. Fluxos, fronteiras, híbridos: palavras-chaves da antropologia transnacional. Mana, Rio de Janeiro, v. 3, n. 1, p. 7-39, 1997.

49. HANNERZ, Ulf. Transnational connections: culture, people, places. London: Routledge, 1996.

50. HERSKOVITS, Melville. African gods and catholic saints in New World Negro belief. American Anthropologist, New York, v. 39, n. 4, p. 635-643, 1937.

51. HUGGAN, Graham. The postcolonial exotic: marketing the margins. London: Routledge, 2001.

52. LÉVI-STRAUSS, Claude. O pensamento selvagem. Campinas: Papyrus, 1989.

53. LEVITT, Peggy. God needs no passport: immigrants and the changing american religious landscape. New York: New Press, 2007.

54. MACHADO, Igor (ed.). Um mar de identidades: a imigração brasileira em Portugal. São Paulo: Edufscar, 2006.

55. MAGGIE, Yvonne. Guerra de orixá: um estudo de ritual e conflito. Rio de Janeiro: Zahar, 1975.

56. MARCUS, George E. Ethnography in/of the world system: the emergence of multisited ethnography. Annual Review of Anthropology, Palo Alto, v. 24, p. 95-117, 1995. 
57. MARTES, Ana Maria. Os imigrantes brasileiros e as igrejas em Massachusetts. In: REIS, Rossana, SALES, Teresa (ed.). Cenas do Brasil Migrante. São Paulo: Boitempo, 1999. p. 87-122.

58. MEINTEL, Deirdre; HERNANDEZ, Annick. Transnacional authenticity: an Umbanda temple in Montreal. In: ROCHA, Cristina; VÁSQUEZ, Manuel. The diaspora of brazilian religions. Leiden: Brill, 2013. p. 223-248.

59. MEIRELLES, Mauro. Religião em tempos de globalização e transnacionalização religiosas: a produção da crença e a reinvenção de tradição a partir do contato intercultural entre diferentes sujeitos e instituições. Debates do NER, Porto Alegre, ano 13, n. 22, p. 305-328, 2012.

60. MIRANDA, Ana Paula; CORRÊA, Roberta de Mello. Religiões e política: controvérsias e agendas contemporâneas em torno da liberdade religiosa em Portugal. In: RESENDE, José Manuel; VICENTE, Inês Pedro; BEIRANTE, David; GOUVEIA, Luís (org.). A governação à lupa das operações críticas: os limites do (in)suportável e do (in) tolerável das políticas e das ações públicas. Carvaçais: Lema d’Origem, 2019. p. 51-83.

61. MONTERO, Paula; SILVA, Aramis Luis; SALES, Lilian. Fazer religião em público: encenações religiosas e influência pública. Horizontes Antropológicos, Porto Alegre, ano 24, n. 52, p. 131-164, 2018.

62. ONG, Aihwa. Flexible citizenship: the cultural logics of transnationality. Durham: Duke University Press, 1999.

63. OOSTERBAHN, Martijn; VAN DE KAMP, Linda; BAHIA, Joana. Global trajectories of brazilian religion: lusospheres. Londres: Bloomsbury, 2020.

64. ORO, Ari Pedro. Religião e mercado no cone-sul: as religiões afro-brasileiras como negócio. In: REUNIÃO ANUAL DA ANPOCS, 22., 1998, Caxambu. Anais [...]. Caxambu: Anpocs, 1998.

65. ORTNER, Sherry B. Poder e projetos: reflexões sobre a agência. In.: GROSSI, Miriam Pillar; ECKERT, Cornelia; FRY, Peter Henry (org.). Conferências e diálogos: saberes e práticas antropológicas. Brasília, DF: ABA, 2007. p. 45-80.

66. PADILLA, Beatriz. Brazilian migration to Portugal: social networks and ethnic solidarity. In: ENCONTRO DA ASSOCIAÇÃO DE ESTUDOS LATINOAMERICANOS, 2006, San Juan. Anais [...]. Lisboa: CIES-ISCTE, 2006.

67. PATARRA, Neide Lopes. Migrações internacionais de e para o Brasil contemporâneo: Volumes, fluxos, significados e políticas. São Paulo em Perspectiva, São Paulo, v. 19, n. 3, p. 23-33, 2005.

68. PONTES, Luciana. Mulheres brasileiras na mídia portuguesa. Cadernos Pagu, Campinas, n. 23, p. 229-256, 2004. 
69. PORDEUS JÚNIOR, Ismael. Portugal em transe: Transnacionalização das religiões afro-brasileiras: conversão e performances. Lisboa: ICS, 2009.

70. PORDEUS JÚNIOR, Ismael. Uma casa luso-afro-portuguesa com certeza: emigrações e metamorfoses da umbanda em Portugal. São Paulo: Terceira Margem, 2000.

71. POVOA NETO, Helion. Migração na Europa: desafios na Itália e nos países da área mediterrânea. In: PAIVA, Odair da Cruz (org.). Migrações internacionais: desafios para o século XXI. São Paulo: Memorial do Imigrante, 2007. p. 51-63.

72. RIBEIRO, Claudio de Oliveira. Dupla e múltipla pertença religiosa no Brasil. Estudos de Religião, São Paulo, v. 32, n. 3, p. 93-115, 2018.

73. RIBEIRO, Gustavo Lins. Antropologias mundiais: cosmopolíticas, poder e teoria em antropologia. Série Antropologia, Brasília, DF, v. 379, p. 1-16, 2005.

74. ROCHA, Cristina; VÁSQUEZ, Manuel A. O Brasil na nova cartografia global da religião. Religião e Sociedade, Rio de Janeiro, v. 34, n. 1, p. 13-37, 2014.

75. ROCHA, Cristina; VÁSQUEZ, Manuel A. (org.). The Diaspora of Brazilian religions. Lieden: Brill, 2013.

76. RODRIGUES, Ricardo Santos. Entre o passado e o agora: diáspora negra e identidade. Revista EPOS, Rio de Janeiro, v. 3, n. 2, p. 1-17, 2012.

77. ROETT, Riordan. The New Brazil. Washington: Brookings Institute Press, 2010.

78. SANCHIS, Pierre. Religiões, religião: alguns problemas do sincretismo no campo religioso brasileiro. In: SANCHIS, Pierre (org.). Fieis e cidadãos: percursos do sincretismo no Brasil. Rio de Janeiro: Eduerj, 2001.

79. SARAIVA, Clara. Afro-Brazilian religions in Portugal: bruxos, priests and pais de santo. Etnográfica, Lisboa, v. 14, n. 2, p. 265-288, 2010.

80. SARAIVA, Maria Clara Ferreira de Almeida. Pretos velhos across the Atlantic: Afro-Brazilian cults in Portugal. In: ROCHA, Cristina; VÁSQUEZ, Manuel A. (org.). The diaspora of Brazilian religions. Lieden: Brill, 2013.

81. SHERRINGHAM, Olivia. Transnational religious spaces: faith and the Brazilian migration experience. Basingstoke: Palgrave Macmillan, 2013.

82. SILVA, Inga Scharf da. Naturgeschichte, Körpergedächtnis: Erkundungen einer kultu $\neg$ ran-thropologischen Denkfigur. Konnex: Studien im Schnittbereich von Literatur, Kultur und Natur. In: BARTL, Andrea; SCHOTT, Hans-Joachim (org.). Trauma als Wissensarchiv. Ambivalenzen zwischen Kollektivem Bildgedächntnis und Verkörperungen am Beispiel der Caboclas und Caboclos in der Umbanda. Würzburg: Königshausen \& Neumann, 2014.

83. SIMMEL, Georg. La lucha. In: SIMMEL, Georg (ed.). Sociología: estudios sobre las formas de socialización. 2. ed. Madrid: Biblioteca de la Revista de Occidente, 1977. 
84. SIQUEIRA, Sueli. Brasileiros em Portugal e a percepção das diferenças culturais e preconceito. In: CONGRESSO PORTUGUÊS DE SOCIOLOGIA, 8., 2014, Évora. Anais [...]. Évora: Universidade de Évora, 2014.

85. SLOTERDIJK, Peter. Esferas I: bolhas. São Paulo: Estação Liberdade, 2016.

86. SOARES, Edio. Le butinage religieux: pratiques et pratiquants au Brésil. Paris: Éditions Karthala, 2009.

87. TAVARES, Fátima Regina; DUARTE, Joelma do Patrocínio; COGNALATO, Rosana Pontes. Movimento nova era e a reconfiguração do social (da contracultura à heterodoxia terapêutica). Antropolítica, Niterói, n. 28, p. 177-196, 2010.

88. TEISENHOFFER, Viola. Umbanda, new age et psychothérapie: aspects de l'implantation de l'Umbanda à Paris. Atéliers d'Anthropologie, Nanterre, n. 31 , p. $1-17,2007$.

89. TÖLÖLYAN, Khachig. Estudos da diáspora: Passado, presente e promessa. Translatio, Porto Alegre, n. 13, p. 22-39, 2017.

90. VAN DE KAMP, Linda. The transnational infrastructures of Luso-Pentecostal mega cities. New Diversities, [s. l.], v. 19, n. 1, p. 1-17, 2017.

91. VAN DE KAMP, Linda. Violent conversion: Brazilian Pentecostalism and urban women in Mozambique. Woodbridge: James Currey, 2016.

92. VOGEL, Arno; MELLO, Marco Antonio da Silva; BARROS, José Flavio Pessoa de. Galinha D’Angola: iniciação e identidade na cultura afro-brasileira. Rio de Janeiro: Pallas, 2001.

93. WELZ, Gisela. Multiple modernities: the transnationalisation of Cultures. In: CONFERENCE TRANSCULTURAL ENGLISH STUDIES, 2004. Anais [...]. Frankfurt: ASNEL/GNEL, 2004. 